\title{
The Strategically Manageable University: Perceptions of Strategic Choice and Strategic Change among Key Decision Makers
}

\author{
Nicoline Frølich ${ }^{1}$, Bjørn Stensaker ${ }^{1}$, Lisa Scordato ${ }^{1} \&$ Paulo Charles Pimentel Bótas ${ }^{2}$ \\ ${ }^{1}$ NIFU Nordic Institute for Studies in Innovation, Research and Education Oslo, Norway \\ ${ }^{2}$ University of Liverpool, Liverpool, England, United Kingdom \\ Correspondence: Nicoline Frølich, Nordic Institute for Studies in Innovation, Research and Education, Postboks \\ 5183 Majorstuen, 0302 Oslo, Norway. Tel: 47-22-595-138. E-mail: Nicoline.frolich@nifu.no
}

Received: August 14, $2014 \quad$ Accepted: September 13, $2014 \quad$ Online Published: September 20, 2014
doi:10.5539/hes.v4n5p80
URL: http://dx.doi.org/10.5539/hes.v4n5p80

\begin{abstract}
One common way of conceptualising recent changes in university governance is by stating that the universities are being pushed towards a market-like setting where the uniqueness of each university's strategy and capacity for introducing organizational change is seen as necessary to improve the functioning of the university. We argue that the strategic functioning of the university is conditioned by the extent to which key decision makers, in the strategic decision-making process, share interpretations of the university's strategic advantages and hence have a coherent view of the strategic choices to be made. Our discussion is based on an analysis of a unique survey among principal decision makers at 26 universities in 8 countries in Europe.
\end{abstract}

Keywords: autonomy, boards, higher education policy, strategy, university governance

\section{Introduction}

In recent years, many universities in Europe have been subjected to governance reforms and measures have been put in place to improve their room for manoeuvre and strategic capacity (Amaral et al., 2003; Amaral et al., 2009; Huisman, 2009; Paradeise et al., 2009). One common way of conceptualising these changes is by stating that the universities are being pushed towards a market-like setting. In this setting, the university's strategy and capacity for introducing organizational change is seen as necessary to improve the functioning of the university's organization. In response to the reforms and measures, the universities have introduced changes to their internal governance and management structures (Bleiklie et al., 2011; Paradeise et al., 2009). In general, like public administration, they have also, adopted a range of organizational practices aimed at improving the accountability and efficiency of universities, possibly adding to a more rational management and administration of their institutions. Such measures, amongst others, include changes in the governing board by reducing numbers of board members while simultaneously increasing the number of external representatives to strengthen the influence of stakeholders on the strategic direction of the universities (Kretek et al., 2012). Nevertheless, perspectives underlining the pluralistic nature of the university organisation provide a contrasting view with the interpretation of universities as strategic actors. The argument is that universities traditionally have organised their activities in disciplines, each with specific disciplinary norms and values, which lead to diverging goals and priorities internally (Becher \& Trowler, 2001). Because of internal goal conflicts, any attempt at formulating overarching objectives and strategies on behalf of the organisation as a whole will inevitably become ambiguous and vague (Cohen et al., 1972). The two approaches to university strategy would lead to different expectations as to how universities deal with strategy formulation and implementation.

In this respect, how universities interpret their environments and their own positioning within their particular fields is an important strategic matter. Such interpretations of environments and the positions of universities are vital in identifying options, and in agreeing on a strategic direction within the institutions by comparing their desired position within a given field with their perceived position (Greenwood \& Hinings, 1996). Nevertheless, organizational change also depends on the strategic capacity of institutions, not least regarding whether or not organizations can act coherently (Weick, 1976). Our argument is that an essential matter in this regard is the extent to which central actors, in the strategic decision-making process, share key interpretations and have a coherent view of the strategic choices to be made. In this article we explore this issue by addressing the following two questions: 
1) To what extent do key decision makers share interpretations of the strategic advantages of their university?

2) To what extent do they share interpretations of the organizational changes the university has been able to bring about?

Our discussion is based on an analysis of a unique empirical survey among principal decision makers at 26 universities in Europe conducted in 2011, produced within the framework of the Transforming Universities in Europe (TRUE) project. The key decision makers (board members, senate members and central administrators) were asked to rate the importance of a number of potential strategic advantages (research, teaching, third mission etc.) of their university. They were further asked about the extent to which their universities had been able to bring about changes in the last decade in strategically important organizational areas (funding, study programs, research priorities and marketing).

\section{Strategic Change in Universities}

At the heart of the debate on strategic changes in universities is the question to what extent and in what meaning universities can be conceived as strategic actors. These questions can be discussed from two main analytical views. On the one hand, universities can be perceived "as any kind of organisation", and on the other hand, universities can be considered as unique organisations with special challenges with regard to acting as a strategic actor (Brunsson \& Sahlin-Andersson, 2000; Krücken \& Meier, 2006).

Based on the "any kind of organisation" perspective, the policy agendas introduced in higher education and public administration in general, as well as the managerial changes in universities over the last decades, increase the relevance of classical insights from theories of strategy in order to explore empirically the extent to which university strategies work as strategic devices in an instrumental sense.

Thus, according to Porter's (1985) theory on competitive advantages, strategy is an internally consistent configuration of activities that distinguishes the organization from its rivals. The main argument is that competitive advantages of organisations are connected directly to activities - rather than size, market share, strengths and weaknesses, key success factors and distinctive competencies, all of which have been key analytical concepts in strategy studies. Strategy is not only a broad vision but represents the particular configuration of activities to be adopted. Hence, Porter's perspective would direct the attention at the strategic priorities and the organizational changes that universities introduce in order to distinguish itself in the higher education market. Moreover, an important implication of Porter's perspective is that organizations have a choice concerning their strategic development that is based on their unique characteristics and positioning in a market.

In contrast, theories of global scripts (Greenwood \& Hinings, 1996) offer another perspective on the element of strategic choice universities have. A global script perspective emphasizes the need for universities to adapt to global challenges in a more standardized way by downplaying country-specific regulations and unique characteristics (Hazelkorn, 2008). In this perspective universities are urged to develop more general competencies that will enable them to compete for world class excellence (Salmi, 2009).

These two perspectives point to two very different outcomes. The competitive advantages perspective hints at diversification within the higher education sector, in the sense that universities introduce strategic change in order to distinguish themselves from another. While the global script perspective suggests the emergence of a more standardized higher education sector, in the sense that universities become more similar. In the context of our research questions, the competitive advantages perspective would lead us to expect universities to have different views on what their strategic advantages are, while the global script perspective would cause us to expect that the differences are less visible and that the universities have a rather similar view on strategic advantages. In similar vein, the competitive advantages perspective would lead us to expect universities to be different with regard to the main organizational changes that had taken place (to support the unique profile of the university), while the global script perspective suggests that the universities again show large similarities in the organizational changes they have been able to bring about.

While the competitive advantages and the global script perspectives result in different expectations and outcomes regarding diversity of the higher education sector, they both take as their starting points that organizations are coherent and manageable entities in the sense that they are capable of making strategic choices. Both perspectives view universities as organisations capable of implementing purposively introduced changes in their ways of operating based on an organisational strategy, which is seen as an instrument for organizational change. From these perspectives on organizational change, it can be foreseen that these organizations will increasingly be turned into formal organizations where strategies function as tools to "steer" them. If universities are becoming strategic actors, we expect them to be able to single out unique strategic profiles and to introduce 
organizational changes that support the realization of their strategies. Similarly, the global script perspective shares the view of universities as coherent actors, though the implications regarding uniqueness and diversity are reversed. Rather than expecting diversity, this perspective expects more of similarities, but still on rational reasons.

In contrast to the "any kind of organization" perspective on universities as strategic actors, there is a consistent research tradition that consecutively argues that universities are decoupled and pluralistic almost by default (Cohen et al., 1972; Weick, 1976). In this perspective, universities are unique kinds of organisations with particular challenges regarding strategic action. According to it, organizational strategies are mainly organizational window-dressing and ceremonial in their functioning (Meyer et al., 2007; Meyer \& Rowan, 1977), as universities depend heavily on the good will of their external stakeholders, they implement organizational strategies in order to be considered as legitimate organizations. Based on this reasoning, university strategies are heavily influenced by the demands of the external environment to which the organization must (formally) conform in order to warrant its legitimacy (DiMaggio \& Powell, 1983). Organizational strategies in the context of highly institutionalized organizations (Selznick, 1957), such as universities, are likely to remain decoupled from daily organizational practices (Meyer \& Rowan, 1977) and, accordingly, have limited influence on organizational change.

This perspective on university organization also offers an important interpretation of contemporary organizational changes. In this context, "steering" in university organizations takes place in organizations that are pluralistic by default (Denis et al., 2007), which influences the strategy process as well as the impact of strategies on organizational change. In the words of Denis et al. (2007, p. 182), universities as pluralistic organizations 'represent a complex challenge for would-be-strategists'. According to the authors, pluralistic organizations generate at least three types of problem for coupling strategies with organizational action: Firstly, these organizations are based on individual autonomy, which allows for flexibility and local development, which in turn allows the individuals to dissociate themselves from centrally established orientations (loose coupling). Secondly, a large degree of participative strategizing in universities, which ensures consensus is achieved at the cost of realism of their strategies. Thirdly, partly digested strategies can be found as sedimented layers in the organization, because the need for change and the means to implement them have to be negotiated through the same people and processes, due to the diffuse power basis. Denis et al. (2007, p. 182) state that "clearly rational models of strategic management are of limited assistance in understanding or confronting these challenges, precisely, because they tend to assume away pluralism" (emphasis added).

Based on the pluralistic view of universities, the effective implementation of strategies is hampered by the organizational configuration of universities. Universities are pluralistic organizations almost by default, where multiple objectives diffuse power and knowledge-based work processes (Denis et al., 2007; Jarzabowski \& Wilson, 2002) are essential characteristics of the university organization. Hence, in an attempt to reach organizational consensus, diverging goals and perceptions at the sub-organizational levels give rise to ambiguous and vague organizational goals (Cohen et al., 1972). The loosely-coupled character of the organizations permits the formal structure to be detached from the actual organizational behaviour, which is presumed to be only slightly affected by the strategy.

The decoupled and pluralistic perspective on universities leads us to expect a much less coherent and meaningful picture of university strategies. On the one hand, it would be expected that the universities converge with the global script expectation in terms of disposing largely similarities regarding strategic advantages; however, in this case, this convergence is based on copying and imitation processes and not due to rational coherent strategizing. On the other hand, the decoupledness of the university organization would hamper rational introduced organizational change. In addition, the pluralistic element would lead us to expect that the senior management of the university might show less coherent views on the strategic advantages and the suitable means for organizational change than both the competitive advantages and the global script perspectives assume.

\section{Data and Method}

The data were sampled from a survey conducted in 2011 among senate members, board members, rectors and central administrators in 26 universities in Norway, Portugal, UK, the Netherlands, Switzerland, Germany, France and Italy. In total 929 participants were invited to respond to the survey, out of which we received 452 answers (response rate 49 per cent). The response rate among universities does vary between 26 per cent and 82 per cent of the total sample of key decision makers at each university (see Appendix A). 
The sample of universities was based on a selection of criteria including one comprehensive research university, one technical/specialized university as well as one less prestigious university (e.g. a previous college turned into a university with a low score on research intensity) from each of the participating countries.

To capture the extent to which key decision makers share interpretations of the strategic advantages of their university, board (council) and senate members were asked to rate the importance of a number of strategically important issues. The scale ranged from extremely important (1) to not important at all (5) at a five points Likert scale.

The formulation of the question in the survey was as follows: How important are each of the following issues in giving your university strategic advantage?

- Quality of teaching

- Quality of research

- Quality of third mission activities

- Institutional infrastructure (buildings etc.)

- Quality of support infrastructure (sports, student services etc.)

- Employment rates of graduates

- Starting salaries of graduates

- Low costs of study

- Geographical location of the institution

- Selective access

- Non-selective access

- Prestige of the institution

To explore to what extent the key decision makers share interpretations of the organizational changes the university has been able to bring about, the board (council) and senate members, as well as central administrators of these universities, were asked to rate the extent to which they perceived that the university had brought about organisational changes in the last five to ten years. Also for this question, a five point Likert scale was used.

The question in the survey was formulated as: To what extent has your university been able to bring about changes in the following areas in the last five to ten years?

- Internal resource allocation

- Resource acquisition

- Amendments in the educational provision

- Adjustments of student numbers

- Setting of research priorities

- Human resource management

- Marketing and public relations

We have used the intra-class correlation coefficient (ICC) to measure the variation in key decision makers' answers on questions about strategic advantages and organizational changes. The ICC is a descriptive statistic that can be used when quantitative measurements are made on units that are organized into groups. It decomposes the variation in individual (within-group) variation and at group level (between-group). It is often used as a first step in multi-level analyses, but in our case, it is used to measure the extent to which key decision makers within each university have similar views on the importance of the listed strategic advantages and organizational changes, compared to the total group of decision makers across universities. Hence, in our case the ICC measures the extent to which the variation in perceptions of the key decision makers (units), within universities, can be considered as more important than variation between universities (groups). Thus, using ICC as a guiding tool, it is possible to assess at what level (unit or group) the interesting variation in the key decision makers' answers can be found.

\section{Empirical Findings}

In the survey, we asked board (council) and senate members to rate the importance of assumed strategic advantages their university could dispose (see Table 1). ICC above 10 per cent indicates that key decision 
makers within the university, to a large extent, share views on the strategic importance of the issue in question, in the sense that, on this matter, there is systematic variation between the universities. ICC below 10 per cent indicates that there is not much systematic variation between the universities. However, ICC below or above 10 per cent is an arbitrary measure like similar statistical measures. Based on this reasoning, we apply the ICC as an indicator of the extent to which key decision makers have shared perceptions of strategic advantages and the amount of organizational change at their university.

Table 1. The importance of strategic advantages within and between universities

\begin{tabular}{ll}
\hline Strategic advantages & ICC at the level of universities \\
\hline Quality of teaching & $6 \%$ \\
Quality of research & $6 \%$ \\
Quality of third mission & $7 \%$ \\
Institutional infrastructure (buildings etc.) & $8 \%$ \\
Quality of support infrastructure (sports, student services etc.) & $6 \%$ \\
Employment rates of graduates & $17 \%$ \\
Starting salaries of graduates & $8 \%$ \\
Low costs of study & $10 \%$ \\
Geographical location of the institution & $10 \%$ \\
Selective access & $9 \%$ \\
Non-selective access & $12 \%$ \\
Prestige of the institution & $22 \%$ \\
\hline
\end{tabular}

Note. Explained variance (ICC) at the level of universities

Table 1 shows the variation between key decision makers within and between universities. On a number of strategic issues, the variation in perceptions of key decision makers within universities is larger than the variation between universities. Key decision makers' perceptions of the importance of quality of teaching as strategic advantage vary more between the decision makers (units), than between universities (groups) (ICC 0.06). In similar vein, the key decision makers' perceptions of the importance of the quality of research as strategic advantage (ICC 0.06), the quality of third mission (ICC 0.07 ), the quality of the institutional infrastructure $(0.08)$ and the quality of the support structure (ICC 0.06) vary to a larger extent within universities, than between them. Also, with regard to the strategic importance of the starting salaries of graduates (ICC 0.8) and selective access (ICC 0.9), the variation within key decision makers within universities is larger than the variation between universities. The key decision makers have different views on these strategic matters within universities. Our interpretation is that, on theses strategic matters, there is a lack of shared interpretations of their strategic advantage within universities.

However, the key decision makers' perceptions' of the importance of the employment rates of graduates as a strategic advantage vary systematically between universities (ICC of 0.17 ). Hence, regarding the strategic advantage of the employment rate of graduates, there are systematic differences between universities. There are systematic variations between the universities on: how important low costs of study are to the strategic profile of the university (ICC 0.1); the strategic importance of the geographical location of the university (ICC 0.1); the strategic importance of non-selective access (ICC 0.12), however, regarding non-selective access, the variation between the universities is systematic to a degree that can't be ignored; and prestige, which is also a strategic advantage of the university that distinguishes between the universities of the sample (ICC 0.22). Our interpretation is that, on these matters, key decision makers have shared perceptions regarding the strategic importance of these issues within universities. We draw the implication that employment rates of graduates, low costs of study, the geographical location of the university, and the prestige of the university are strategically important advantages to the universities in the sense that key decision makers have shared views on these matters within universities. 
Now we turn to the extent to which key decision makers at the universities have shared views regarding the extent to which the university has been able to bring about strategic organizational change in the last five to ten years (Table 2).

Table 2. The extent to which the university has been able to bring about strategic changes in the last five to ten years

\begin{tabular}{ll}
\hline Strategic change in the last 5 to 10 years & ICC at the level of universities \\
\hline Internal resource allocation & $9 \%$ \\
Resource acquisition & $10 \%$ \\
Amendments in the educational provision & $3 \%$ \\
Adjustment of student numbers & $14 \%$ \\
Setting of research priorities & $10 \%$ \\
HR & $7 \%$ \\
Marketing & $7 \%$ \\
\hline
\end{tabular}

Note. Explained variance (ICC) at the level of universities

Table 2 shows that key decision makers within universities do not have shared interpretation of the extent to which their university has been able to bring about strategic organizational change regarding internal resource allocation (ICC 0.9), amendments in the educational provision (ICC 0.3), human resources (ICC 0.7) and marketing (ICC 0.7).

However, regarding the extent to which the university has been able to bring about organizational change in adjustment of student numbers (ICC 1.4), resources acquisition (ICC 1.0) and setting of research priorities (ICC $1.0)$, it can be noticed that the variation between universities is larger than the variation in perceptions within universities. Thus, among key decision makers, these areas are considered areas in which the university has been able, to a larger or smaller extent, to bring about organisational change.

\section{Discussion and Conclusion}

The results of the analysis indicate that key decision makers at 26 European universities have shared views within the university regarding the strategic importance of the following areas: prestige of the university, geographical location of the university, low costs of study, non-selective assess and employment rates of graduates. However, key decision makers within the universities do not share the interpretation of the strategic importance of the quality of teaching, research, third mission, support structure, selective access and the starting salaries of graduates.

In similar vein, key decision makers have shared views on the extent to which their university has been able to bring about change in relation to the adjustment of student numbers, resource acquisition and the setting of research priorities. While key decision makers do not have shared views on the extent to which their university has been able to bring about change in strategically important measures like internal resource allocation, educational provision, human resources, and marketing.

In support of the competitive advantages perspective, the results show that, on some strategically important areas, there is systematic variation between the universities. Likewise, on some dimensions of organisational change, there is systematic variation between the universities regarding the extent to which they have been able to bring about change the last few years. It is, however, not possible to assess straight forward whether the universities are becoming more similar or not-e.g., the support to the expectation that universities are developing in line with the competitive advantages expectations or the global script expectations. The ICC measures the extent to which there is systematic variation between universities, but it does not measure in detail the strength of the variation. One might, perhaps based on the results of the analysis, suggest that the prestige of the university as well as the importance of the employment rates of graduates are strategic areas that differentiate to a larger extent between the universities, than the other strategic areas. Likewise, the adjustment of student numbers distinguishes better between them, than the other managerial tools. In line with this interpretation, the support to the standardised strategy implementation expected from the global scripts, might be in place. 
However, in our view, the striking result is the extent to which key decision makers at these universities do not agree on the strategic advantages of their university, neither on the extent to which organizational changes have been put in place. For us, this points in the directions of the fact that pluralism and diverging views are still a prevailing characteristic of the universities' strategy processes. As expected from the pluralistic perspective on university strategizing, the senior management of the university might show less coherent views on the strategic advantages and the suitable means for organizational change than both competitive advantages and the global script perspectives assume.

One interpretation could be that universities find it easier to relate strategically to loosely defined concepts such as, the prestige of the university, and the employability of graduates, than to the concepts of quality of research, teaching, and third mission that they provide. The findings resonate with the pluralistic and loosely coupled perspectives in the sense that key decision makers find it difficult to agree on the quality of the core activities, while umbrella concepts like prestige and employability are more easily agreed upon. Yet, costs of study and entrance regulations are issues that are more manageable and, on these matters, key decision makers at the individual university agree on their strategic importance.

If these organizations had clearly been rational in an instrumental sense, we might have expected internal resource allocation mechanisms and adjustments of the educational offer to have played a more prominent role in the assessment of the strategic advantages of the university. Yet, we found that universities had been able to bring about changes, in varying degrees, in important managerial practices such as, resource acquisition, student numbers and research priorities.

It is important to point out that, when analysing strategic advantages and organizational change in universities as perceived by key decision makers, the ICC analysis yields interesting insights on the extent to which strategic issues and organizational changes are consistently viewed internally among university managers. In conclusion, our findings suggest that universities, to some extent, are clearly unified on certain important strategic domains such as, prestige and employability. They also have a coherent view on the extent to which organizational changes have been brought about regarding research priorities, student numbers and resource acquisition. However, universities are clearly not coherently strategic actors in the sense that key decision makers assess their strengths, weaknesses and change similarly. Rather, the pluralistic character of the universities is essentially present: Key decision makers do not make coherent assessments of the importance of quality of their core activities, or of the extent to which the individual university has been able to bring about change in educational provision, internal resource allocation, marketing and HR. Thus the strategically manageable university is still in the making.

\section{Acknowledgements}

The survey data were produced within the framework of the Transforming Universities in Europe (TRUE) project, which is a large-scale collaborative work aimed at understanding the organizational transformation of universities in the European context. TRUE was financed by the European Science Foundation.

Erica Waagene has contributed to the data gathering and Joakim Caspersen has contributed with valuable methodological advice and comments.

\section{References}

Amaral, A., Meek, V. L., \& Larsen, I. M. (2003). The higher education managerial revolution. City: Kluwer Academic Publisher: Dordrecht. http://dx.doi.org/10.1007/978-94-010-0072-7

Amaral, A., Neave, G., Musselin, C., \& Maassen, P. (2009). European intergation and the governance of higher education and research. Springer: Dordrecht. http://dx.doi.org/10.1007/978-1-4020-9505-4

Becher, T., \& Trowler, P. (2001). Academic tribes and territorities: intellectual enquiry and the culture of the disciplines (2nd ed.). London Routledge.

Bleiklie, I., Enders, J., Lepori, B., \& Musselin, C. (2011). New Public Management, Network Governance and the University as a changing professional organization. In T. Christensen, \& P. Lægreid (Eds.), The Ashgate research companion to New Public Management. Farnham: Ashgate Publishing Limited.

Brunsson, N., \& Sahlin-Andersson, K. (2000). Constructing organizations: The example of the public sector reform. Organization Studies, 721-746. http://dx.doi.org/10.1177/0170840600214003

Cohen, M. D., March, J. G., \& Olsen, J. P. (1972). A garbage can model of organizational choice. Administrative Science Quarterly, 17, 1-25. http://dx.doi.org/10.2307/2392088

Denis, J.-L., Langley, A., \& Rouleau, L. (2007). Strategizing in pluralistic contexts: Rethinking theoretical 
frames. Human Relations, 60(1), 179-215. http://dx.doi.org/10.1177/0018726707075288

DiMaggio, P. J., \& Powell, W. W. (1983). The iron cage revisited. Institutional isomorphism and collective rationality in organizational fields. American Sociological Review, 48, 147-160. http://dx.doi.org/10.2307/2095101

Greenwood, R., \& Hinings, C. R. (1996). Understanding radical organizational change: Brining together the old and new institutionalism. Academy of Management Review, 21, 1022-1054.

Hazelkorn, E. (2008). Learning to live with league tables and rankings: The experience of institutional leaders. Higher Education Policy, 21(2), 193-215. http://dx.doi.org/10.1057/hep.2008.1

Huisman, J. (2009). International perspectives on the governance of higher education. Alternative frameworks for coordination. City: Routledge, Taylor \& Francis group: London and New York.

Jarzabowski, P., \& Wilson, D. C. (2002). Top teams and strategy in a UK university. Journal of management studies, 39(3).

Kretek, P., Dragsic, Z., \& Kehm, B. (2012). Transformation of university governance: On the role of university board members. Higher Education.

Krücken, G., \& Meier, F. (2006). Turning the university into an organizational actor. In G. S. Drori, J. W. Meyer, $\&$ H. Hwang (Eds.), Globalization and organization: world society and organizational change. Oxford: Oxford University Press.

Meyer, J. W., Ramirez, F. O., Frank, D. J., \& Schofer, E. (2007). Higher education as an institution. In P. J. Gumport (Ed.), Sociology of higher education, Contributions and their contexts (pp. 187-221). Baltimore Johns Hopkins University Press.

Meyer, J. W., \& Rowan, B. (1977). Institutional Organizations: Formal structures as myth and ceremony. American Journal of Sociology, 83, 340-363. http://dx.doi.org/10.1086/226550

Paradeise, C., Reale, E., Bleiklie, I., \& Ferlie, E. (2009). University Governance. Western European Comparative Perspectives. City: Springer: Dordrecht. http://dx.doi.org/10.1007/978-1-4020-9515-3

Porter, M. (1985). The Competitive Advantage: Creating and Sustaining Superior Performance. NY: Free Press.

Salmi, J. (2009). The challenge of establishing world-class universities. The World Bank. http://dx.doi.org/10.1596/978-0-8213-7865-6

Selznick, P. (1957). Leadership in Administration. New York: Harper \& Row.

Weick, K. E. (1976). Educational organizations as loosely coupled systems. Administrative Science Quarterly, 21, 1-9. http://dx.doi.org/10.2307/2391875

\section{Appendix A}

\section{Overview of data -Universities by country and response rates}

\begin{tabular}{lllll}
\hline Type of university & Age & Total, by institution & \\
\hline & & Number of responses & Sample & Response rate (per cent) \\
\cline { 3 - 5 } Comprehensive & Old & 6 & 12 & $\mathbf{5 0}$ \\
Comprehensive & Young & 9 & 12 & $\mathbf{7 5}$ \\
Specialist & Young & 8 & 12 & $\mathbf{6 7}$ \\
Specialist & Young & 9 & 14 & $\mathbf{6 4}$ \\
Total Norway & & $\mathbf{3 2}$ & $\mathbf{5 0}$ & $\mathbf{6 4}$ \\
Comprehensive & Young & 35 & 69 & $\mathbf{5 1}$ \\
Comprehensive & Old & 19 & 73 & $\mathbf{2 6}$ \\
Specialist & Old & 24 & 62 & $\mathbf{3 9}$ \\
\hline
\end{tabular}




\begin{tabular}{|c|c|c|c|c|}
\hline Total Italy & & 78 & 204 & 38 \\
\hline Specialist & Young & 25 & 40 & 63 \\
\hline Comprehensive & Old & 27 & 35 & 77 \\
\hline Specialist & Young & 9 & 21 & 43 \\
\hline Total Portugal & & 61 & 96 & 64 \\
\hline Comprehensive & Young & 10 & 22 & 45 \\
\hline Specialist & Old & 13 & 21 & 62 \\
\hline Comprehensive & Old & 14 & 26 & 54 \\
\hline Total Netherlands & & 37 & 69 & 54 \\
\hline Specialist & Old & 8 & 21 & 38 \\
\hline Comprehensive & Old & 20 & 41 & 49 \\
\hline Comprehensive & Young & 17 & 28 & 61 \\
\hline Total Germany & & 45 & 90 & 50 \\
\hline Comprehensive & Old & 48 & 86 & 56 \\
\hline Specialist & Old & 27 & 33 & 82 \\
\hline Specialist & Young & 7 & 10 & 70 \\
\hline Specialist & Young & 12 & 19 & 63 \\
\hline Comprehensive & Old & 30 & 42 & 71 \\
\hline Total Switzerland & & 124 & 190 & 65 \\
\hline Comprehensive & Old & 34 & 109 & 31 \\
\hline Comprehensive & Young & 16 & 38 & 42 \\
\hline Specialist & Young & 12 & 31 & 39 \\
\hline Total UK & & 62 & 178 & 35 \\
\hline Specialist & Old & 6 & 30 & 20 \\
\hline Comprehensive & Young & 7 & 22 & 32 \\
\hline Total France & & 13 & 52 & 25 \\
\hline Total all & & 452 & 929 & 49 \\
\hline
\end{tabular}

\section{Copyrights}

Copyright for this article is retained by the author(s), with first publication rights granted to the journal.

This is an open-access article distributed under the terms and conditions of the Creative Commons Attribution license (http://creativecommons.org/licenses/by/3.0/). 